\title{
Invisibilidade e visibilidade dos refugiados palestinianos no campo jordano de jerash : o filme documental "remember us"
}

Invisibilité et visibilité des réfugiés palestiniens dans le camp jordanien de jerash : le documentaire " remember us » Invisibility and visibility of palestinian refugees in the jerash camp in jordan : the documentary " remember us »

Isabel Babo e Vanessa Ribeiro Rodrigues

\section{OpenEdition}

Edição electrónica

URL: http://journals.openedition.org/ctd/990

DOI: $10.4000 /$ ctd. 990

ISSN: 2491-1437

\section{Editora}

Chaire Unesco Pratiques émergentes en technologies et communication pour le développement

\section{Edição impressa}

Data de publição: 30 outubro 2016

ISBN: 2491-1437

\section{Refêrencia eletrónica}

Isabel Babo et Vanessa Ribeiro Rodrigues, «Invisibilidade e visibilidade dos refugiados palestinianos no campo jordano de jerash : o filme documental "remember us" ", Communication, technologies et développement [En ligne], $3 \mid$ 2016, mis en ligne le 30 octobre 2016, consulté le 12 juin 2020. URL : http://journals.openedition.org/ctd/990 ; DOl : https://doi.org/10.4000/ctd.990 


\title{
Invisibilidade e visibilidade dos refugiados palestinianos no campo jordano de jerash : o filme documental "remember us"
}

\author{
Invisibilité et visibilité des réfugiés palestiniens dans le camp jordanien de \\ jerash : le documentaire "remember us" \\ Invisibility and visibility of palestinian refugees in the jerash camp in jordan : \\ the documentary « remember us »
} Isabel Babo e Vanessa Ribeiro Rodrigues

\section{Introdução}

1 Os refugiados palestinianos oriundos de Gaza, a viver na Jordânia, sobretudo aqueles que vivem no campo de Jerash, têm um estatuto legal diferenciado em relação aos outros refugiados palestinianos ${ }^{1}$. Não são reconhecidos como cidadãos - não tendo um número de identidade, não são elegíveis a direitos civis e sociais - constituindo uma minoria invisível que não integra um espaço público institucional ou em vias de formação. Neste sentido, é uma comunidade que nem é pública, nem visível, nem configurada publicamente, já que as precárias condições de sobrevivência não constituem um assunto de denúncia pública e de indignação moral na sociedade jordana, em parte, provavelmente, porque que se trata de um regime misto composto por princípios constitucionais e islâmicos e, nesse enquadramento, sem uma verdadeira "cultura de problemas públicos" (Gusfield, 1981) equivalente à das sociedades democráticas.

2 Para dar voz e rosto a essa minoria, a cineasta palestiniana Dalia Abuzeid realizou o documentário "Remember Us", entre 2013 e 2014, e usou as redes digitais (Facebook, Vimeo, alojamento web yolasite, zoomal) para publicitar e conferir visibilidade a esta 
causa, através de um discurso e exposição que constroem uma narrativa sobre o problema.

3 Neste texto, pretende-se inquirir e analisar em que medida o uso das plataformas digitais online organiza uma inteligibilidade do fenómeno conferindo-lhe visibilidade e existência pública enquanto problema social tornado "problema público" (Gusfield, 1981) no espaço público jordano e no que se poderá considerar a esfera pública global de comunicação. Para tal, e após breve apresentação do documentário, colocar-se-á em discussão a noção de espaço público e os novos espaços públicos, a fim de, mais adiante, interrogar-se se poderá aplicar-se esse conceito ao contexto de um campo de refugiados e, a um outro nível, à própria sociedade jordana. Para esta análise e, sobretudo, para compreender o alcance da publicitação do campo de Jerash, através do documentário, convocam-se as categoria de publicidade, visibilidade e espaço comum de Hannah Arendt, assim como se referem questões da mobilidade e acessibilidade de Isaac Joseph. Recorre-se, igualmente, ao debate sobre a existência de espaços públicos concorrentes, alternativos ou subalternos e de contra-públicos, de acordo com as reflexões de Nancy Fraser, atestando a existência de uma pluralidade de espaços públicos, na constituição dos quais importa hoje refletir sobre o papel desempenhado pelas novas tecnologias de comunicação e informação. Coloca-se, por isso, a questão se as redes digitais online são o lugar de uma designada automobilização e mass self-communication (Manuel Castells), provocando, em certa medida, uma privatização e individualização de carácter informacional e eletrónico das mobilizações.

4 A partir de um corpus de textos retirados das plataformas de publicidade do documentário, do discurso do vídeo promocional na plataforma de crowdfunding, de um artigo de média jordano e de um artigo italiano sobre o filme, colocar-se-á também a questão de saber até que ponto a publicitação do campo de Jerash tornou o problema dos refugiados palestinianos num problema público dotado da visibilidade e, por aí, de existência.

\section{Tornar público. Espaços e meios de visibilidade e publicidade}

\section{"Remember Us"}

O documentário de Dalia Abuzeid ${ }^{2}$ sobre os refugiados palestinianos move-se em torno das questões centrais da vulnerabilidade e da falta de dignidade, tornando visível uma realidade oculta que perdura há muitos anos. $\mathrm{O}$ objetivo é : "revelar histórias não contadas dos refugiados de Gaza, na Jordânia", "ajudar o mundo a lembrar-se deles", uma vez que são "desprovidos de direitos humanos básicos, de direitos civis e sociais", vivendo como "cidadãos de terceira classe", "sem esperança de um futuro melhor" modo para dar conta desta realidade será, não a definição de "quem são" (sabemos que o uso de categorias implica processos de enquadramento que detêm uma inscrição (cultural) $)^{4}$, mas a configuração da sua realidade e do que são e vivem através de discursos e ações. Na linha de autores como John Dewey, é na comunicação, na participação, nas consequências da ação nos outros e em si mesmo e na conversação que o indivíduo se constitui (mind emerge) 5 . Como diria Arendt (1958), é através das histórias que revelam as suas ações que os indivíduos se manifestam ${ }^{6}$. 
Como propósito de "abrirosolhos"

dasautoridadesparaaquestãoedarvisibilidadeauma"minoria esquecida" num contexto de "perda de direitos" e violação de direitos humanos fundamentais, Dalia Abuzeid, no filme documental que realiza, realça as "condições desumanas em que vivem" e as "limitações", porque são "cidadãos de lado nenhum". Enunciação que também se constrói pela negativa ou pela ausência de : não têm direitos, não têm lugar. Este campo semântico é o quadro (frame, de acordo com a frame analysis de Erving Goffman, 1991) que permite dar voz e rosto a esta comunidade, tornando-a pública. Ao mesmo tempo, o filme incita ao envolvimento do espectador e leitor na causa, fazendo-o "testemunha da vida dura, diária" destes refugiados, criando uma possibilidade de participação. Como declara a autora :

"This documentary will tackle the situation of a forgotten minority in Jordan; Palestinian refugees from Gaza living in Jerash Camp that is also known for Gaza Camp in the town of Jerash. (...) Unlike other Palestinian refugees, Gaza Camp refugees have no Jordanian National number, which leads them to live in tough conditions related to health, education, and financial situations" (Website Remember Us). "The documentary will lead the audience to not just witness the daily tough life, but live it as well with an interesting raw interactive style. We believe this film will open the eyes of both governments and individuals around the world to the inhumane conditions they are living under" (Zoomal, plataforma de crowdfunding).

7 Como consequência, emergiu no espaço público mediático jordano a publicação de uma notícia de promoção do documentário e da campanha de crowdfunding no jornal nacional Jordan Times, com versões em papel e online. Essa notícia repercute o discurso de Dália Abuzeid ("este filme vai abrir os olhos dos governos e dos indivíduos à volta do mundo "), reinscrevendo-se no campo semântico que o filme documental adotou das questões de cidadania e das "histórias não contadas", em que surgem as categorizações (membershpis categorizations; H. Sacks e L. Jayyusi) "cidadão de lado nenhum" e "minoria esquecida" que organizam uma inteligibilidade da situação e dos protagonistas. Assim como fica clara a identificação dos propósitos sociais do documentário : "um esforço para fazer alguma coisa pelos refugiados palestinianos na Jordânia", "promover a consciência global" sobre o assunto e "auxiliar em campanhas de ajuda social" de maneira a responder aos problemas sociais e emocionais ${ }^{7}$. 0 momento discursivo em que Dália Abuzeid assume claramente que "não [lhe] interessa a política", mas a dignidade e a humanidade dos refugiados como "projeto humanitário", como "seres humanos a ajudar seres humanos", é, primeiro, no vídeo promocional da campanha de crowddfunding em que reforça que "precisa" da ajuda de todos para "lançar luz à fronteira dos conflitos". Depois, mantém este ponto de vista numa entrevista a uma revista online de estudos políticos (Osservatori Iraqui) ${ }^{8}$. A jovem autora considera o projeto como "uma ponte" de abertura aos outros e de reconhecimento (dar-se a ver e a conhecer, poderíamos dizer), mas também assume que o documentário é uma forma de dar visibilidade à sua própria narrativa e identidade, enquanto refugiada palestiniana, e de preservar a memória da sua família9

O seu discurso cruza assim as questões de cidadania e de ordem política (“...elevar a ideia de política neste filme, e regressar à origem: seres humanos a ajudar seres humanos"), com as narrativas pessoais ("por favor ajude-nos a contar a nossa história"), criando a possibilidade de identificação de si mesmo e construção da sua própria identidade, mas também da ligação e adesão (projeção) por parte dos leitoresespectadores com as histórias contadas, no que poderá ser lido, à luz de Manuel 
Castells, como automobilização. Esta ideia, no quadro do pensamento deste autor, vincula- se ao que ele teoriza como a nova forma histórica de comunicação global, pessoal e interativa nos media electrónicos, que ele designa de "auto-comunicação de massas" ou "comunicação de massa individual" (mass self-communication, Castells). Designação contraditória nos termos, que enfatiza a extensão ilimitada das mediações electrónicas em situações de uso ligadas a contextos privados e individuais.

Coloca-se, por isso, de seguida, a questão das potencialidades das redes digitais sociais enquanto dispositivos e lugares de publicidade, visibilidade e participação, assim como de instauração e alargamento de espaços públicos.

\section{Os novos espaços públicos}

Convocar a noção de espaço público no âmbito do discurso filosófico da modernidade é remeter, desde logo, para a noção de opinião pública e para a livre discussão de ideias que obedece ao princípio da publicidade formulado por Kant e para a teoria de Jürgen Habermas $\left(1986^{10}\right)$, em que o espaço público moderno é estruturado pelo uso público da razão argumentativa. Mas as noções de espaço público e de "público", no sentido de tornar público ou dar a conhecer, que se tornaram basilares enquanto conceitos operatórios, assumem diferentes acepções. Em Hannah Arendt (A condição do homem moderno, 1958), público significa o que aparece e é visível e o que é "comum" (mundo comum). o espaço comum do "viver em conjunto" constitui o meio sensível e o espaço de visibilidade no qual as ações e as palavras, os agentes e os acontecimentos acedem à sua existência, adquirem os traços que os identificam e abrem-se ao juízo público. Para a sociologia urbana (nascida no âmbito da ecologia urbana, na Escola de Chicago), os espaços públicos urbanos ligam-se à realidade topológica das interações e relações interpessoais, da acessibilidade, da visibilidade, da impersonalidade, do anonimato e das comunidades locais. Nos modos de vida urbanos e no espaço público, como assinala Isaac Joseph $(1995,1999)$, colocam-se as questões da acessibilidade, mobilidade e locomoção (nos espaços acessíveis a qualquer um : rua, parque, gare, galeria comercial, mercado, etc.), as questões da porosidade dos espaços, dos regimes de exposição, de representação, de ação, reunião e copresença, assim como as relações do visível e do invisível.

"A experiência comum de um espaço público obriga-nos com efeito a não dissociar espaço de circulação e espaço de comunicação. Uma gare, uma estação de metro, um mercado são reputados acessíveis não somente pelas suas qualidade arquiteturais mas pela sua capacidade em articular visibilidades e enunciados. (...) a qualidade de acessibilidade de um espaço público está ligada à legibilidade do seu "modo de uso", tal como está ligada à competência comunicativa dos agentes encarregues de o justificar, i.e. de dar publicamente conta de um espaço e das prestações que ele oferece » (Joseph, $1995: 13)$.

11 Esta concepção de espaço público abarca o carácter cénico, dramatúrgico e ritualístico dos lugares públicos da vida em comum (Goffman, 1973; Sennet, 1979), no seio dos quais os atores públicos se dão em representação, colocam-se em cena perante um público de desconhecidos e desempenham papéis. Tanto quanto as questões de acessibilidade, mobilidade e locomoção demonstram que o espaço público é um lugar de circulação (Virilio [1988, 2014] denuncia que é um derivado do movimento e da velocidade). Ora, são precisamente estas acepções de público e de espaço público, de acordo com os quadros conceptuais e teóricos referidos, em que se interligam as 
dimensões da livre comunicação, da livre circulação e da visibilidade que, justamente, dificilmente se aplicarão a um campo de refugiados, podendo falar-se na ausência de um espaço público. Contudo, autores como Fraser (2003) e Benhabib (2004) apelam a novos modelos "concorrentes", "alternativos" e "porosos" de espaço público, que se alargam a contra-públicos concorrentes que contestaram e contestam as normas do espaço público burguês e elaboram novos estilos de comportamento político e novas formas de discussão pública (Fraser, 2003), assim como se aplicam às minorias sociais, aos refugiados, aos requerentes de asilo (Benhabib, 2004).

Ora, Fraser assevera que as exclusões e também conflitos, que sempre marcaram o espaço público, difundem um ethos específico, mantendo na sombra uma diversidade de públicos plurais e heterogéneos. Estespodemconstituir-seem"contrapúblicossubalternos"(Fraser, 2003) àmargem do espaço público (liberal, burgês) que nunca foi capaz de responder às minorias e à diversidade existente. Esses contrapúblicos podem formar arenas discursivas paralelas, nas quais membros dos grupos sociais subordinados elaboram e fazem circular contra-discursos que lhes permitem difundir a sua própria interpretação das suas identidades (Fraser, $2003: 119)$, dos seus interesses, necessidades e vontades. Nesta medida, estamos indiscutivelmente perante uma multiplicidade de esferas públicas (pós-burguesas) e de públicos plurais e heterogéneos e podemos entender que num campo de refugiados se pode constituir uma proto-esfera-pública (e uma opinião pública) a partir das narrativas partilhadas.

É, justamente, disto que se trata em "Remember Us". Gente "de lado nenhum" pode articular e fazer ouvir os seus discursos sobre questões que lhes dizem respeito e ser dada a ver e a conhecer, ou mostrar-se e revelar-se, no espaço público mediático sem fronteiras.

Se concordarmos com Arendt quando proclama que "ser e aparecer coincidem" ${ }^{11}$, afirmação esta da qual decorre a concepção de espaço público constituído pelas dimensões sensível e visível, enquanto "cena pública de aparição" na qual as coisas são vistas e ouvidas - aquilo que "aparece em público e pode ser visto e ouvido por todos" e enquanto o lugar de formação do juízo, entenderemos que, muito embora o domínio público também seja o espaço comum do "viver em conjunto", ele significa sobretudo o visível, mais do que comum. O "viver em conjunto" político não decorre do estar em conjunto ou da comunidade, mas da visibilidade ou do "aparecer comum dos seres". É questão da polis enquanto alicerce dos intervalos que ligam sem juntar nem integrar :

“O espaço público é o espaço de interação social e significativa onde as ideias e os valores se formam, se transmitem, se garantem e defendem; espaço que em última instância se torna o campo de preparação para a ação e a resposta. Por isso, ao longo da história, o controle da comunicação social pelas autoridades políticas e ideológicas e pelos ricos era fonte decisiva do poder social. Isto é o que acontece na sociedade em rede, agora mais do que nunca. (...) As redes de comunicação multimodal constituem, em conjunto, o espaço público na sociedade em rede, de tal modo que as diferentes formas de controle e manipulação das mensagens e da comunicação no espaço público estão no centro da construção do poder « (Castells, 2009 : 395-396) ; "Mas num mundo marcado pelo crescimento da autocomunicação de massas, existem muitas oportunidades para que movimentos sociais e políticas emergentes entrem no espaço público. Utilizando tanto as redes de comunicação horizontais como os principais média para disseminar mensagens e imagens, aumentam as suas possibilidades de promover a mudança política e cultural" (Ibidem : 397). 
Os média tradicionais de massa, os novos média e produções como o filme documental em análise neste texto, possibilitam justamente a proliferação de uma multiplicidade de públicos "concorrentes" e "alternativos", conferindo visibilidade, logo existência pública, a grupos sociais subordinados ou sem direitos, e a espaços públicos plurais nos quais se veiculam e difundem diferentes discursos em diversos contextos. Já Habermas, no prefácio (1992) que dedicou à reedição da sua obra Espaço Público, admitia uma pluralidade de espaços públicos inacabados e de fronteiras permeáveis (locais, regionais, internacionais, partidários, literários, mediáticos, científicos, políticos, subculturais, etc.). As esferas públicas pluralizam-se e reconfiguram-se nessa miríade de arenas, hoje mediadas pelas ligações tecnológicas, como as redes sociais digitais, no que vem sendo designado "arquiteturas informativas reticulares" (Massimo di Felice, 2012).

\section{Internet : espaços públicos mediatizados e automobilização}

16 A internet, de acordo com o modelo reticular de ligações entre uns e outros - "Modelo no qual a informação navega de forma distribuída, horizontal, dialógica e redundante e onde cada nó tem igual importância e poder de interdependência" (Massimo di Felice, 2012: 30) - é o modelo da sociabilidade em linha e dos média participativos, estabelecendo a comunicação many to many em oposição ao modelo one to many dos média tradicionais.

Nas redes sociais fluem e convivem diversas plataformas de comunicação e interação de utilizadores e públicos, introduzindo novas modalidades comunicacionais no espaço público que se subtraem aos dispositivos clássicos de vigilância e aos discursos dominantes. Essas novas modalidades comunicacionais permitiram o uso da liberdade de expressão na denominada Primavera Árabe, em 2011, na Tunísia e no Egito, rompendo com a censura e o controlo da informação a que os média tradicionais estavam submetidos pelos regimes autocráticos em vigor. As redes sociais emergiram, então, como o suporte comunicacional e de informação das manifestações.

“Estas ligações e novas modalidades comunicacionais e também jornalísticas tornam-se utensílios nas formas do público a vários níveis: ao nível da multiplicação das mediações, ou seja, dos meios e dispositivos usados na circulação e troca de informações e notícias, e dos meios de formação das opiniões públicas (no plural) ; ao nível da pluralização (e fragmentação) dos espaços públicos (locais, regionais, nacionais, internacionais ; políticos, culturais, constituídos por questões de cidadania, etc.) ; ao nível da diversidade dos públicos" (Babo, 2013 : 802).

18 Nas redes comunicacionais as vozes pluralizam-se. Podendo discutir-se o regime de autonomia de cada um e de organização coletiva, Castells considera que nas redes sociais irrompe uma "auto- organização e a auto-mobilização da sociedade", que supera as barreiras da censura e repressão impostas pelo Estado :

"El espacio público es el espacio de la interacción social y significativa donde las ideas y los valores se [orman, se transmiten, se respaldan y combaten; espacio que en última instancia se convierte en el campo de entrenamiento para la acción y la reacción. Por eso, a lo largo de la historia, el control de la comunicación socializada por parte de las autoridades ideológicas y políticas y de los ricos era fuente determinante del poder social. Esto es lo que ocurre en la sociedad red, ahora más que nunca. (...) las redes de comunicación multimodal constituyen, en conjunto, el espacio público en la sociedad red de tal manera que las diferentes formas de control y manipulación de los mensajes y de la comunicación en el espacio público están en el centro de la construcción del poder" (Castells, 2009 : 395-396). 
19 Através da visibilidade, das discussões e debates, como por exemplo comentários no Facebook, fóruns online ou reuniões públicas, é possível reconfigurar publicamente um assunto problemático para uma minoria e exercer pressão sobre o discurso dominante. Neste sentido, aplica-se o que Castells designa de "comunicação de massa individual" (mass self-communication) ou "auto- comunicação de massas", de acordo com uma tendência à individualização das mobilizações informacionais, mesmo que em torno de uma causa ou de um problema tornado público. Na internet vigoram trocas interpessoais (no prolongamento do correio e do telefone) e, ao mesmo tempo, a comunicação de massa (no prolongamento da rádio e da televisão) engendrando o que vem sendo apelidado de "comunicação interpessoal de massa" (Baym, 1998, apud Mercklé, $2011: 11)$.

Os média sociais podem, assim, ser um lugar de mobilização discursiva para discutir problemas e questões de indivíduos em minoria, de públicos alternativos ou subalternos, que de outra forma ficariam ausentes ou com reduzida presença e visibilidade nos meios de comunicação tradicionais (imprensa, rádio e televisão). Criar uma página de Facebook, um blogue, um website, uma conta de twitter, uma campanha de crowdfunding para a realização de um filme documental que, por sua vez, configura uma causa humana ou humanitária, trata-se de dotar minorias de um discurso comum. As denúncias ou reivindicações que assim tomam forma, podem vir a constituir um (contra-)espaço público desterritorializado, com potencial disseminação viral e de fluxos, não alcançando, contudo, o mesmo nível de participação e comprometimento que o espaço público territorial ocupado pelos atores e pelos meios de comunicação tradicionais. Embora hoje se assista a mobilizações públicas iniciadas online que se revertem em protestos de rua ${ }^{12}$ ou em ocupações de espaços (praça Tahrir, Gezi Park, Puerta del Sol, etc.). Nesse sentido, é importante colocar a questão da possibilidade de existência de um espaço público local, num campo de refugiados, e da existência de um espaço público jordano.

\section{(Im)Possibilidade de existência de um espaço público em contexto não democrático}

\section{O espaço público jordano}

21 O Reino Hachemita da Jordânia, país criado em 1947 sua depois da sua independência do Reino Unido, é uma monarquia constitucional com um sistema de governo alicerçado na separação de poderes, segundo o modelo do estado de direito. Contudo, difere dos Estados de Direito democráticos na medida em que reparte o sistema legal de uma forma mista entre a Lei Civil e a Lei Islâmica. Surge assim e desde logo, uma dificuldade quando se trata de aplicar o conceito de espaço público a países não democráticos, se mantivermos o modelo de espaço público que se formou e consolidou nos estados de direito democráticos, enquanto lugar da livre discussão pública de ideias e de formação das opiniões e das vontades políticas, e de vigilância dos poderes públicos. Em Habermas (1986), com efeito, o espaço público designa o lugar do debate e do uso público da razão argumentativa (sendo o lugar de uma comunicação democrática e dos meios de comunicação), onde são discutidas as questões práticomorais e políticas, garantindo a legitimidade do poder. 
22 Tal não impede que não se possa falar de um espaço público jordano estruturado pelos discursos dos média tradicionais e da existência de espaços públicos alternativos, não submetidos aos poderes públicos, ondesecruzamtrocasdeideias, vontades, conflitos. Maisespecificamente, fala-se deesfera pública política na Jordânia, da participação dos jovens, da reforma política no Médio Oriente, dos diferentes estatutos legais dos refugiados palestinianos e da respectiva restrição de acesso à vida pública. Na obra “ State Interests and Public Spheres: The International Politics of Jordan's Identity" (1999), Marc Lynch, diretor do Institute for Middle East Studies and the Middle East Studies Program da Universidade George Washington, nos Estados Unidos, contextualiza a teoria da esfera pública de Habermas na Jordânia. Preocupa-se, primeiramente, em estabelecer o impacto da identidade jordana e o peso que os interesses nacionais têm na política externa jordana. Ainda que o autor esteja focado mais na influência que a esfera pública internacional, no Médio Oriente, tem na identidade jordana e nos interesses nacionais, usa a teoria habermasiana para explicar a forma como a opinião pública e os interesses nacionais se formam na Jordânia. $O$ conceito da esfera pública surge para explicar o nível de responsabilidade que os governos têm para as suas decisões políticas. Lynch explica que, na ausência de uma "esfera pública efetiva", pode considerar- se que o Estado dispõe de uma considerável autonomia da definição do que é o interesse nacional. O autor aplica, assim, a teoria de Habermas sobre o espaço público ao contexto do Médio Oriente e liga, explicitamente, a força da esfera pública às ações e interesses do governo. Nessa mesma linha, Sean L. Yom, investigador em assuntos políticos do Médio Oriente e autor de "Society and Democratization in the Arab World" (2005), defende que o conceito de sociedade civil, conforme é considerado na Europa Ocidental e nos Estados Unidos, não se aplica necessariamente às sociedades do Médio Oriente. Yom é cético em relação ao poder político que as sociedades civis têm no mundo árabe, enquadrando os resultados do estudo de Krista Vendetti (2012), "Jordan Public Sphere: Understanding the Youth Awareness and Perceptions of the Constitutional Reforms in the Post-Arab Spring Era", de que os jordanos têm acesso limitado, em geral, ao espaço público. Aliás, a esfera pública política jordana enfrenta problemas significativos em termos de inclusão e igualdade. A investigadora conclui que as políticas governamentais desencorajaram fortemente os jovens jordanos a se envolver em atividades públicas e, em especial, as mulheres experienciam uma elevada exclusão económica, social e política.

23 É neste contexto que terá de ser colocada a questão dos refugiados palestinianos, as suas condições de existência, direitos e vida em comum.

\section{Refugiados palestinianos}

24 A Jordânia continuará ainda a ser, na atualidade, o país que mais campos de refugiados tem - treze no total, mas sem uma Lei para os Refugiados, uma vez que não é país signatário da Convenção de Genebra das Nações Unidas (1951). É assim que parte da sua herança cultural e étnica provém, precisamente, dessa mescla de refugiados oriundos da Palestina, da Síria e do Líbano que acolheu ao longo dos anos, nomeadamente a vaga de exilados Palestinianos de 1947, no contexto do conflito israelo-árabe (ano da formação do Estado de Israel) e a vaga de 1967-68, no contexto do novo conflito bélico israelo-árabe, quando a maioria de refugiados estava a ser empurrada desde Gaza para a Jordânia. Hoje, a Jordânia debate-se com os fluxos de refugiados provenientes da Síria ${ }^{13}$, sobretudo, mas também do Iraque ${ }^{14}$. Se na primeira vaga, os refugiados foram 
oriundos da Cisjordânia, que se encontra geográfica e historicamente ligada à Jordânia, estando hoje integrados na sociedade jordana com direitos civis, os refugiados da segunda vaga, em 1967, oriundos de Gaza que então estava sob jurisdição egípcia, não tiveram, até hoje, reconhecidos quaisquer direitos civis e sociais, estando confinados a um passaporte válido, temporariamente, por dois anos e sem direito a acesso a várias atividades laborais. Tal condição restritiva estende-se ainda aos descendentes filhos de pais palestinianos oriundos de Gaza, embora nascidos na Jordânia, que herdam a identidade paternal.

"Ex-Gaza Palestine Refugees are one of the most vulnerable groups in Jordan. While most Palestinian refugees have been granted Jordanian citizenship and may enjoy the related full rights, the refugees who originally came from Gaza Strip and took refuge in Jordan after the Arab Israeli war of 1967 do not enjoy Jordanian citizenship. They are entitled to hold temporary Jordanian passports which are valid for two years only. In addition to serving as travel documents, these passports are used as an identification document and residency permit. The limited validity of their passports, which are expensive to obtain, severely limits the possibilities for these individuals to travel and gain employment abroad. Their lack of citizenship translates into several legal restrictions that limit their rights and contribute to their vulnerable living conditions (...). Ex-Gaza refugees cannot vote, work for the government (except on a casual basis), and benefit from government services. Access to domestic employment by (larger) private companies may also be denied, as national Intelligence may not grant the required approval. Also certain government licenses, like public drivers' license, are not granted to ex-Gaza refugees. The ex-Gaza refugees often lack the skills, licences and resources to start their own small business. Further, they do not afford higher education, as they have to pay disproportionate tuition fees" (The United Nations Refugee Agency, Refugee Tribunal Review, Australia, 2009).

Este cenário constitui o quadro de um grave problema social, no qual também se incluem outros problemas como o alcoolismo, o desemprego, a pobreza, a insalubridade, a discriminação social. Ora, desde o momento em que a comunidade internacional tem conhecimento e é alertada para a existência destes problemas, eles constituem-se em "problemas públicos", focando sobre si a atenção coletiva.

De acordo com Gusfield (1981), os "problemas públicos" são problemas sociais em que o que está em jogo são questões de ordem pública. Ou seja, "são problemas sociais construídos, tematizados e tratados nas arenas públicas (media, associações de cidadãos, partidos políticos, tribunas políticas (...) o que supõe uma prática colectiva de definição e de formulação destes problemas" (Gusfield, 1981, apud Babo, 2006 :109). Neste sentido, a existência de determinados problemas sociais pode, em determinada altura, pelo seu alcance e impacto numa determinada comunidade, tornar-se num problema público que constitua "assunto de discussão nas arenas públicas e tenha sido constituída em objecto de uma ação pública" (idem). Deve, porém, realçar-se que o modo como os problemas são formulados, tratados e tematizados, e o modo como retêm a atenção pública, não são idênticos em todos os casos e em todos os momentos.

27 Para Gusfield, determinar se um problema social é um problema público compreende três critérios : deve comportar um ou vários aspectos inaceitáveis para uma sociedade num determinado momento; deve ser constituído um assunto de controvérsia, de debate e de conflito nas arenas públicas e requerer tratamento por uma ação pública. É por isso que nem sempre os problemas sociais se configuram em problemas públicos, sendo requerido que adquiram uma dimensão societal. 
Ora, o caso dos refugiados palestinianos oriundos de Gaza, a viver no campo de Jerash, na Jordânia, constitui um problema social, mas pode afirmar-se que não havia sido construído em problema público no sentido de eclodir publicamente como contendo aspectos inaceitáveis para a sociedade jordana em geral, constituindo um assunto de controvérsia, de debate e conflito de opiniões nas arenas públicas. Sabe-se que este problema existe e é a própria lei jordana que impõe o estatuto diferenciado de refugiado palestiniano de Gaza, sem direito à cidadania jordana, de modo a instituir uma modalidade de legalização do problema. Nesta medida, estes refugiados são uma minoria invisível, sem acesso à esfera pública, por isso não participantes num espaço público comum. Integram uma comunidade que nem é visível, nem configurada publicamente. Acresce ainda que, mesmo as precárias e degradantes condições de sobrevivência dos refugiados palestinianos no campo de Jerash, não constituíam um assunto de denúncia pública e de indignação moral.

Poderá dizer-se que na sociedade jordana falha uma "cultura dos problemas públicos", de acordo com a concepção de Gusfield, não dispondo quer de "dispositivos de identificação do carácter problemático das situações, quer de maneiras instituídas de tematizar estas situações problemáticas e de as tratar" (Gusfield, 1981, apud Babo, 2006 : 113-114). Como Louis Queré (2001) advoga, a constituição dos problemas sociais em problemas públicos pressupõe a existência do referencial do Estado de direito democrático, o que não acontece nas arenas públicas jordanas.

\section{Visibilidade dos refugiados palestinianos de Jerash}

\section{Dar voz e rosto à "minoria esquecida"}

O documentário "Remember Us", filmado entre 2013 e 2014 no campo de refugiados de Jerash, na Jordânia, também conhecido como Gaza camp pelo facto de acolher os refugiados palestinianos oriundos de Gaza (em 1968), torna visível esta minoria, como vimos, cujo estatuto legal na Jordânia os confina à invisibilidade.

Para Arendt, o domínio público integra as duas dimensões já anteriormente referidas ${ }^{15}$, essenciais para o exercício da cidadania e da liberdade : o mundo comum de artefactos, ações, instituições e valores que separa os humanos da natureza e que lhes confere contexto relativamente permanente e de longevidade para as suas atividades ; o espaço de visibilidade e de aparecimento (ou de "aparição"), espaço de liberdade no qual as ações e as palavras ${ }^{16}$, os agentes e os acontecimentos acedem à sua verdadeira existência, adquirem os traços que os identificam e abrem-se ao juízo público. É nesta situação de aparecimento (aparição) e de mundo comum que os indivíduos podem estabelecer relações de reciprocidade e de solidariedade e usufruir das suas identidades. Viver em sociedade é viver com os outros e, como tão bem Arendt explicou, a condição humana é uma "condição de pluralidade" ${ }^{17}$, pelo facto de que são os homens e não o homem que vivem na terra e habitam o mundo.

Ora, o que a jovem realizadora propõe com "Remember Us" é, precisamente, o aparecimento e existência pública dos refugiados palestinianos oriundos de Gaza que não têm acesso à cidadania no contexto do espaço público jordano. E fá-lo, por um lado, através das histórias pessoais de resistência e superação, através das estratégias de comunicação online (a plataforma de crowdfunding Zoomal, o website com informações sobre o projeto e a criação do Grupo de Facebook), concedendo-lhes deste modo vida 
pública, voz e rosto, um presente e um futuro. Por outro lado, e como consequência, origina diversos públicos (jordano e públicos diferenciados internacionais), apelando ainda ao seu envolvimento com esta causa.

\section{Configuração de uma "minoria esquecida" a partir de um filme documental}

33 Apesar de a realizadora afirmar que não detinha um objetivo político com esta publicitação, o filme documental e a plataforma de crowdfunding encerravam, de facto, o propósito da participação cívica, focalizando a atenção pública, através do discurso utilizado, para a questão desta "minoria esquecida", dos "cidadãos de lado nenhum" e chamando "a atenção de governos e indivíduos" para uma questão histórica que se arrastava, "esquecida". Ou seja, constituiu uma ação de denúncia humanitária com uma carga inevitavelmente política, conferindo existência pública aos refugiados, apelando aos seus direitos e a respostas cívicas, e organizando uma outra inteligibilidade do fenómeno enquanto problema público que fixa sobre si a atenção coletiva e requer a intervenção dos poderes públicos para a sua resolução.

O filme documental "Remember Us" criou uma narrativa composta de várias histórias dos refugiados a viver no campo de Jerash, de forma a "contar a história deles", fazendo-os ser e aparecer, para não permanecerem esquecidos. As estratégias de publicitação utilizadas pela realizadora Dalia Abuzeid, através das redes digitais, promoveram o documentário, conferiram visibilidade ao problema e interpelaram o público jordano e os públicos internacionais, produzindo em certa medida o que poderá designar-se de automobilização individual para apoiar o filme.

Mas existe uma outra questão importante que perpassa a configuração narrativa e a publicitação do problema e que se prende com o próprio processo de identificação e, poderia dizer-se, reconhecimento. A jovem Dalia Abuzeid, que tem estatuto de refugiada palestiniana apesar de não viver no campo, cronstrói a narrativa a partir da sua própria história, para dar inteligibilidade e sentido e também perpetuar a su aprópriavida(oseupassado, presenteefuturo) e, simultaneamente, para conferir estatuto à "minoria esquecida". A forma como tenta construir uma narrativa doadora de sentido a essas existências no espaço público jordano e global é realizada através dos discursos sobre o problema nas plataformas utilizadas, assumindo o registo da temporalidade - a situação que se arrasta há tanto tempo e é tempo de agir - e o registo da mobilização cívica de indivíduos e ou de coletivos: "seres humanos a ajudar seres humanos", como ela exorta.

\section{Para concluir}

O filme documental "Remember Us" criou uma narrativa composta de várias histórias dos refugiados a viver no campo de Jerash, de forma a "contar a história deles", fazendo-os ser e aparecer, para não permanecerem esquecidos. As estratégias de publicitação utilizadas pela realizadora Dalia Abuzeid, através das redes digitais, promoveram e divulgaram o documentário conferindo visibilidade ao problema e interpelaram quer o público jordano quer os públicos internacionais, produzindo o que poderá designar-se de automobilização individual para apoiar o filme. Ou seja, estamos perante formas individualizadas de comprometimento expressivo na internet (Cardon e 
Granjon, 2013), em que (novos) cidadãos exprimem modos de agir pessoal e, ao mesmo tempo, coletivo.

Nesta medida, o impacto do problema e o alcance mediático ultrapassaram a capacidade que os média tradicionais (imprensa, rádio, televisão) detêm de denunciar um assunto e mobilizar em torno de si as opinões públicas. A plataforma digital constituiu um lugar de participação e adesão, onde foram lançados opiniões e comentários solidários, e se apoiou financeiramente o projecto.

Por fim, as questões que se podem levantar prendem-se, desde logo, com as limitações de acesso à internet num campo de refugiados e da sua livre utilização, e a quase impossibilidade de constituição de espaços públicos de livre comunicação, acessibilidade e circulação em contextos delimitados, não democráticos e com condições de vida deficitárias. Não obstante, e tidas em conta as limitações de participação cívica por parte daqueles que vivem a situação, poderá aludir- se que o uso das redes digitais introduz transformações ao nível das práticas de mobilização e das práticas de participação cívica e política. O que levanta inúmeras questões que vão desde saber em que medida as novas tecnologias comunicativas introduzem mudanças nas formas de interação e intervenção social e política, até analisar como reconfiguram as práticas de ativismo e ajudam à emergência de novas formas de expressão individual e coletiva.

Castells, M. (2009). Comunicación y poder, Alianza Editorial, Madrid, España.

\section{BIBLIOGRAFIA}

Arendt, H. (1988). La condition de l'homme moderne, Paris : Calmann-Levy.

Arendt, H. (1998). The human condition (2nd ed), Chicago : University of Chicago Press.

Babo, I. (2000). A construção dos problemas públicos. Elementos para uma análise do caso Timor, Antropológicas, n.4, pág-113-130. Disponível em :

http://revistas.rcaap.pt/antropologicas/article/view/923/725 [acedido em 20 de Abril de 2015]

Babo-Lança, I. (2006). A Configuração dos Acontecimentos Públicos. O Caso República e as Manifestações nos Açores em 1975. Coimbra : MinervaCoimbra.

Babo, I. (2013). As manifestações na Tunísia e no Egipto em 2010-11. A semântica dos acontecimentos nos media e o papel das redes digitais, Revista Análise Social, 209, XLVIII, (4.․), 2013, pp. 792-809 http://analisesocial.ics.ul.pt/documentos/AS_209_a02.pdf, http:// analisesocial.ics.ul.pt/?page_id=18.

Babo, I. (2015). Espectadores e Públicos Activos, Lisboa : Editora Nova Vega.

Benhabib, S. (2004). The Rights of Others : Aliens, Residents, and Citizens. Cambridge : Cambridge University Press.

Cardon, D. (2011). La démocratie internet. Paris : Seuil. 
Cardon, D. e Granjon, F. (2013). Médactivistes. Paris : Sciences Po, Les Presses.

Castells, M. (2011). A era das wikirrevoluções, Entrevista a Manuel Castells por Jordi Rovira, em 08/03/2011 in Jornal de Debates, edição 632 (acedido em Terça-feira, 07-02-2012.

Dewey, J. (1929). Experience and Nature [Versão electrónica], Chicago \& London : Open Court, 1925 ; revised edition, New York : Norton, 1929 ; London : Allen \& Unwin.

Di Felice, M. (2012). Netativismo : novos aspectos da opinião pública em contextos digitais,

Revista Famecos, Porto Alegre, v.19, n.1, pp. 27-45. http://revistaseletronicas.pucrs.br/ojs/ index.php/revistafamecos/article/view/11339.

Fraser, N. (1992). Rethinking the Public Sphere : A Contribution to the Critique of Actually Existing Democracy. In Craig Calhoun (ed.) Habermas and the Public Sphere (pp. 109-142). Massachusetts : MIT Press.

Goffman, E. (1974). Les rites d'interaction, Paris : Minuit. Goffman, E. (1991). Les cadres de l'expérience , Paris : Minuit.

Gusfield, J. (1981). The Culture of public problems : drinking-driving and the symbolic order, Chicago University of Chicago Press.

Habermas, J. (1978). L'espace public, Paris, Payot.

Habermas, J. (1992). 'L'espace public', 30 ans après, Quaderni, n.ำ18, pp. 161-191.

Jayyusi, L. (1984). Categorization and the moral order, Londres : Routledge \& Kegan Paul.

Joseph, I. (ed.) (1995). Prendre Place. Espace public et culture dramatique, Paris, Éditions Recherches. Joseph, I. (1999). Paisagens urbanas, coisas públicas, Caderno CRH, no30/31, Salvador, pp. -11- 40.

Lynch, M. (1999). State Interests and the Public Sphere: The International Politics of Jordan's Identity. New York : 3Columbia University Press.

Mercklé, P. (2011). Sociologie des Réseaux sociaux, Paris : La Découverte.

Neveu, E. (1999). Médias, mouvements sociaux, espaces publics, Réseaux, 98, p. 17-84. Paquot, T. (2009). L'espace public. Paris : La Découverte.

Quéré, L. (2001). Construction des problèmes publics et action collective, Discursos. Língua, Cultura e Sociedade, Lisboa : Univ. Aberta, pp. 97-113.

Quéré, L. (2011). A individualização dos acontecimentos no quadro da experiência pública, Revista Caleidoscópio 10, Edições Universitárias Lusófona, pp. 13-37.

Renault, e. e Sintomer, y. (dir.) (2003). Où en est la théorie critique ? Paris : La Découverte. Rouet, G. (dir.) (2013). Mobilisations citoyennes dans l'espace public. Paris : L'Harmattan.

Sennett, R. (1979). Les tyrannies de l'intimité, Paris : Seuil.

Snow, D. (2001). Analyse de cadres et mouvements sociaux, Raisons Pratiques, 12, Paris : Ed. EHESS, p. 27-49.

Yom, Sean L. (2005). Society and Democratization in the Arab World, The Middle East Review of International Affairs 9.4

Vendetti, Krista (2012). Jordan's Political Public Sphere : Understanding the Youth's Awareness and Perceptions of the Constitutional Reforms in the Post-Arab Spring Era. Independent Study Project (ISP) Collection. Paper 1275. http://digitalcollections.sit.edu/isp_collection/1275 [acedido a 30 de Abril de 2015]. 
Virilio, P. (2004). Ville panique. Ailleurs commence ici, Paris : Galilée.

Internet (corpus de análise)

Site Remember Us : http://rememberusfilm.yolasite.com/

Site de Campanha de crowdfunding zoomal : http://www.zoomaal.com/projects/remember-us1/

Link do jornal online Jordan Times :http://jordantimes.com/local-filmmaker-seeks-to-expose-

plight-of-jordans-gaza-refugees

The United Nations Refugee Agency, Refugee Review Tribunal, Australia, disponível em : http:// www.refworld.org/pdfid/4b6fe264d.pdf [acedido a 21 de abril de 2015]

\section{NOTAS}

1. Uma primeira versão foi apresentada por Vanessa Ribeiro Rodrigues, em Maio de 2015, no âmbito do programa Doutoral em Estudos em Comunicação para o Desenvolvimento da Universidade Lusófona do Porto, sob orientação de Isabel Babo. O presente artigo é conjunto..

2. Dalia Abuzeid is a Palestinian filmmaker. Originally, from the city of Yaffa, Palestine. Born and raised in Amman, Jordan and living with the limitations of having a Gaza Strip ID: A citizen of nowhere, therefore she loses the rights of public medical care, public education and many career options. (...) This documentary will tackle the situation of a forgotten minority in Jordan; (...) (Zoomal, plataforma de crowdfunding).

3. "Remember Us is a feature documentary that will reveal the untold stories of Gaza refugees in Jordan, as a ripple effect of the long-lasting conflict between Palestine and Israel. What happened to the ones that left? What would have happened if they had stayed behind? By filming the refugee status and the reality of Gaza nowadays, we will help the world remember them. Gazarefugees in Jordan are deprived from basic human, civil and social rights, living as thirdclass citizens with little hope for a brighter future. But there are success stories. And we've found them" (Website Remember Us: http://rememberusfilm.yolasite.com

4. Os jornalistas, os media em geral, os poderes públicos, os atores sociais e os públicos ao aplicaremquadros de percepção ecategorização (Jayyusi, 1984) efetuam um enquadramento dentro de um sistema de referências culturais que são parcialmente derivados por códigos culturais preexistentes ou estruturas preexistentes de significação (Snow 2001: 40). Como esclarece Neveu (1999), todo orepertório dequadrodispõederessonânciasculturais, com elementos de uma doxa social. 5. “Through speech a person dramatically identifies himself with potential acts and deeds; he plays many roles, not in successive stages of life but in a contemporaneously enacted drama. Thus mind emerges" (Dewey, 1929: 167).

6. As narrativas de um contador de histórias, argumenta Arendt, "tell us more about their subjects, the 'hero' in the center of each story, than any product of human hands ever tells us about the master who produced it" (Arendt, 1998: 184).

7. "For Dalia Abuzeid, living with a Gaza Strip ID card in Jordan has made her feel like a "citizen of nowhere", whichledher to start filming "Remember Us" in an effort to do something for Palestinian refugees in Jordan.(...) The planned feature-length documentary tackles Jordan's "forgotten minority" - Gazans - said 22-year-old Abuzeid, whostudied filmmaking at the SAE Institute. (...) Abuzeid said the documentary will reveal "untold stories" about the lives of the 
refugees, while raising global awareness and aiding social campaigns to address their daily physical, emotional and social problems. (...) We believe this film will open the eyes of both governments and individuals around the world to the conditions in the camp, and encourage them to help by giving more opportunities rather than taking them away," Abuzeid told The Jordan Times in a recent interview" (in Jordan Times, 1 de Agosto de 2013).

8. "Agora precisamos da sua ajuda, novamente. Estamos perto de atingir o nosso objetivo. Conseguimos assegurar já 50 mil dólares, mas ainda precisamos de outros 15 mil. 46 anos depois, o que aconteceu àqueles que deixaram Gaza? E o que teria acontecido se eles tivessem ficado para trás? Ao filmarmos as histórias ainda não contadas dos refugiados de Gaza no campo de refugiados em Jerash, na Jordânia (...) esperamos lançar uma luz à fronteira dos seus conflitos.. (...) Eles não têm acesso à saúde pública (...) enquanto refugiados de Gaza não podem trabalhar no setor público bem comonão podem ter algumas profissões como dentistas, engenheiros, advogados, contabilistas. E é aqui que todos entramos, queremos elevar a ideia de política neste filme, e regressar à origem: seres humanos a ajudar seres humanos. O meu nome é Dália Abuzeid e sou uma refugiada de Gaza, por favor ajude-nos acontar anossahistória" (in vídeo promocional Remember Us).

9. «Non mi interessa la politica. Con il tempo sono diventata sempre più scettica verso il sistema. A me interessano le storie. Possiamo dire che il nostro è un progetto umanitario: al centro abbiamo messo l'essere umano. Siamo esseri umani che aiutano altri esseri umani ». (...) “Io sono come un ponte: da una parte il campo, con le sue storie e la sua gente, che èanche la mia gente, senza voce; dall'altra il mondo, al quale io posso parlare, da gazawi, da rifugiata e da film maker. Non posso lasciarmi scappare questa occasione: raccontare la storia della mia famiglia, e insieme quella di altre famiglie, di altre persone che hanno fatto tanto per poter raggiungere il propri obiettivi» (in Osservatorio Iraq, 14 Luglio 2013).

10. Habermas, J. (1986). L'Espace Public, tradução francesa de Strukturwandel der Öffentlichkeit, 1962.

11. "No domínio dos assuntos humanos, - garante Arendt - o ser e o aparecer são realmente uma só e mesma coisa"; "Para nós, a aparência - o que é visto e ouvido por outrem como por nós mesmos - constitui a realidade" (Arendt, 1988: 89).

12. De que são exemplos os novos movimentos Geração à Rasca (Portugal, 2011), Occupy Wall Street (2011) queseprolongou poroutrascidade do mundo, Movimiento $15-\mathrm{M}$ ou Indignados (Espanha, 2011), Que se lixe a Troika (Portugal 2012, 2013, em cidades portuguesas e outras), Não vai ter Copa (contra o Mundial de Futebol de 2014, Brasil), etc. 13. «O campo de refugiados sírios... que é a quarta maior 'cidade' da Jordânia. Há três anos era um deserto. Hoje, Zaatari alberga mais de 80 mil refugiados que fogem de um conflito que teve início em 2010» (15/09/2015, Económico economico.sapo.pt/.../o-campo-de-refugiados- sirios-que-e-a-quarta-maior-c., consultado a 2/01/2016).

14. "GENEBRA, 23 de setembro de 2014 (ACNUR) - O Alto Comissariado da ONU para Refugiados (ACNUR) informou hoje um aumento significativo, nas últimas semanas, no número de iraquianos fugindo de país. ACNUR relata grande aumento no número de iraquianos fugindo para Jordânia e Turquia" (23/09/2014, www.acnur.org/.../acnur-relata-grande-aumentono-numero-de-iraquian... consultado a 2/01/2016).

15. O domínio público é o espaço comum do "viver em conjunto", da publicidade e da visibilidade, daquilo que "aparece em público e pode ser visto e ouvido por todos" (H. Arendt, 1958).

16. Como Arendt alvitra: "o poder só se concretiza onde a palavra e a ação não se divorciam, onde as palavras não são vazias e os actos não são brutais, onde as palvavras 
não são utilizadas para velar intenções mas para revelar realidades e os actos não são usados para violar e destruir, mas para estabelecer relações e criar novas realidades" (Arendt, 1958: 179).

17. "É a presença dos outros vendo o que nós vemos, ouvindo o que nós ouvimos, que nos garante a realidade do mundo e de nós mesmos" (Arendt, 1988: 90).

\section{RESUMOS}

Este texto propõe-se a inquirir e a analisar em que medida o uso das plataformas digitais online contribuíu para dar visibilidade, no espaço público, à minoria de refugiados palestinianos oriundos de Gaza a viver no campo de Jerash, na Jordânia. Para tal, começa por colocar-se em discussão a noção de espaço público e os novos espaços públicos, de maneira a mais tarde se interrogar e aplicar o conceito ao contexto de um campo de refugiados. De seguida, analisa-se um breve corpus de textos retirados das plataformas de publicitação do documentário "Remember Us", do website, do discurso do vídeo promocional na plataforma de crowdfunding, um artigo jordano e um artigo italiano sobre o filme. Considera-se que se trata de uma denúncia humanitária com carga política, dotando as minorias de visibilidade e de um discurso comum e apelando a direitos e respostas cívicas, organizando uma outra inteligibilidade do fenómeno enquanto problema público que foca sobre si a atenção coletiva e requer a intervenção de poderes públicos para a sua resolução.

Ce texte se propose d'interroger et d'examiner dans quelle mesure l'utilisation des plateformes numériques en ligne a contribué à rendre visible, dans l'espace public, la minorité de réfugiés palestiniens provenant de Gaza et qui vivent dans le camp de Jerash en Jordanie. Pour cela, on commence par discuter la notion d'espace public et les nouveaux espaces publics, en vue de, plus tard, examiner et appliquer ce concept au contexte d'un camp de réfugiés. Puis après, on analyse un brève corpus de textes procédant des plateformes publicitaires du documentaire « Remember Us ", du site web, du discours du vidéo promotionnelle sur la plateforme de crowdfunding, aussi bien qu'un article jordanien et un article italien sur le film. Nous admettons qu'il s'agit d'une plainte humanitaire orientée politiquement, donnant aux minorités visibilité et un discours commun, appelant aux droits et réponses civiles, organisant une autre intelligibilité du phénomène comme un problème public qui focalise sur lui l'attention collective et qui convoque une intervention des pouvoirs publics pour sa résolution.

This article proposes to inquire and analyse to what extent the use of online digital platforms contributed to giving visibility in the public sphere to the minority of Palestinian refugees from Gaza, living in Jerash camp in Jordan. In order to do this, first we discuss the notion of public sphere and new public spheres, to later interrogate and apply the concept to the framework of a refugee camp. Afterwards we analyse a text corpus from the online platforms used to publicize the documentary "Remember Us, » such as the website, the promotional video of the crowdfunding platform, a Jordanian article and an Italian article about the film. We assume that it constitutes a humanitarian report politically-charged, giving minorities a common speech, calling for rights and civic responses, settling another intelligibility of the phenomenon as a public problem that claims a collective attention and requires the intervention of public authorities in order to solve them. 
ÍNDICE

Keywords: public sphere, visibility, refugees, digital networks, public problem

Mots-clés: espace public, visibilité, réfugiés, réseaux numériques, problème public

Palavras-chave: espaço público, visibilidade, refugiados, redes digitais, problema público.

\section{AUTORES}

VANESSA RIBEIRO RODRIGUES

Universidade Lusófona do Porto, Portugal 